Energy Research Journal 1 (2): 73-77, 2010

ISSN 1949-0151

(C) 2010 Science Publications

\title{
Synthesis of Nanoparticles of Mixed Oxides Containing Titanium Cerium Silver and Silicon: Phase Transformation
}

\author{
Akkarat Wongkaew, Waree Jansome, Supachai Khemchan, \\ Netnapa Sawaengmit and Sarawadee Mitpapan \\ Department of Chemical Engineering, Burapha University, Chonburi, Thailand, 20131
}

\begin{abstract}
Problem statement: Titanium dioxide is a well known material using with self-cleaning application. This is due to its properties after exposed to UV light: Superhydrophilicity and photocatalysis. The addition of other oxides could prolong these properties without continuing exposed to UV. However, titanium dioxide phase is essential. In order to obtain these properties, titanium dioxide needs to be in anatase phase. Approach: In this Research, phase transformation temperatures of mixed oxide of titanium dioxide and other oxides were determined. Samples of different mixed oxides were prepared by sol gel method. The first sample contained $30 \% \mathrm{TiO}_{2}$ and $70 \% \mathrm{SiO}_{2}$. The second sample contained $30 \% \mathrm{TiO}_{2}, 15 \% \mathrm{CeO}_{2}$ and $55 \% \mathrm{SiO}_{2}$. The last sample contained $30 \% \mathrm{TiO}_{2}$, $15 \% \mathrm{CeO}_{2}$ and $55 \% \mathrm{SiO}_{2}$. Each sample was separately calcined at various temperatures from 350$850^{\circ} \mathrm{C}$ stepping by $50^{\circ} \mathrm{C}$ and followed by grinding and sieving to obtain in the form of powders. Then, each powder was characterized for its microstructure and phases of titanium dioxide, crystallite size by X-Ray diffraction. Results: The results from XRD showed that for a $30 \% \mathrm{TiO}_{2} / \mathrm{SiO}_{2}$, an increase in calcined temperatures from $350-850^{\circ} \mathrm{C}$ (increasing by $50^{\circ} \mathrm{C}$ ) increased average crystallite sizes of titanium dioxide (from 5.1-11.8 nm). Also, titanium dioxide phase found in the samples was only anatase. For a $30 \% \mathrm{TiO}_{2} / 15 \% \mathrm{CeO}_{2} / \mathrm{SiO}_{2}$, an increase in calcined temperatures was not affect to the structure of the samples and XRD patterns seemed to be in an amorphous structure. Finally, for a $30 \% \mathrm{TiO}_{2} / 15 \% \mathrm{AgO} / \mathrm{SiO}_{2}$, titanium dioxide was found in an anatase phase at $350^{\circ} \mathrm{C}$ until $650^{\circ} \mathrm{C}$. Then, at calcined temperatures greater than $700^{\circ} \mathrm{C}$, rutile phase started appearing in the structure while anatase phase peaks slowly declined with an increasing in calcined temperatures. This result showed that using these mixed oxides to coat over glass slides or mirrors for self-cleaning purposes, the films should be treated at certain temperatures to obtain an anatase phase. Conclusion: Phase transformation of titanium dioxide depends on calcined temperatures. The addition of other oxides such as silica, cerium or silver can effectively suppress the anatase-rutile phase transformation and resulted in an increase of anatase-rutile phase transformation temperatures.
\end{abstract}

Key words: Anatase phase, calcination temperatures, titanium dioxide, phase transformation temperature

\section{INTRODUCTION}

Titanium dioxide is of great interest owning to its applications related to photo-splitting of water, photocatalyst, photovoltaic devices and so on (Besor et al., 2009; Meen et al., 2009). Moreover, its thin film can induce hydrophilic surface with a water contact angle of $0-5^{\circ}$ under UV light irradiation. This is so called "superhydrophilicity". This property of $\mathrm{TiO}_{2}$ thin film makes it possible to be utilized for many applications such as anti-fogging or self-cleaning mirrors (Liu et al., 2008). Phases of titanium dioxide affected to superhydrophilic property of the films. The anatase phase in $\mathrm{TiO}_{2}$ thin films resulted in superhydrophilic property (Kontos et al., 2007). Therefore, phases of titanium dioxide are of importance to their applications. The other oxides cooperated with titanium dioxide enhanced photocatalytic and superhydrophilic properties (Houmard et al., 2007). However, the addition of other oxides affected the anatase-rutile phase transformation temperatures (Kumar et al., 1999). In this research, the effect of calcined temperatures to titanium dioxide phase transformation and crystalline sizes of titanium dioxide

Corresponding Author: Akkarat Wongkaew, Department of Chemical Engineering, Burapha University, Chonburi, Thailand, 20131 
mixed with others was studied. The amount of titanium dioxide was kept constant at $30 \%$ wt and the rest is other oxides.

\section{MATERIALS AND METHODS}

Sample preparation: Mixed oxide of titanium dioxide with other oxides was prepared by sol gel method. Titanium isopropoxide obtained from Sigma Aldrich was a titanium precursor. For a $30 \% \mathrm{TiO}_{2} / \mathrm{SiO}_{2}$ preparation, it began with dissolving the desire amount of Tetraethylorthosilicate (TEOS) into ethanol. The solution was stirring for $30 \mathrm{~min}$. and then a stoichiometric amount of water was added into the solution to obtain hydrolysis reaction. The solution was continuing stirring. The known amount of nitric acid was added to peptize the solution. Then, the desire amount of titanium isopropoxide was added into the solution. The solution was kept stirring for $30 \mathrm{~min}$. The obtained solution was aged for overnight and is called "sol". The sol was heated until it became gel. The obtained gel was aged overnight. After aging, the gel was dried at $110^{\circ} \mathrm{C}$ followed by calcined at different temperatures from $350-850^{\circ} \mathrm{C}$ (increased by $50^{\circ} \mathrm{C}$ ). The final oxide was ground and sieved to 100 mesh.

For a $30 \% \mathrm{TiO}_{2} / 15 \% \mathrm{CeO}_{2} / \mathrm{SiO}_{2}$ and a $30 \% \mathrm{TiO}_{2} / 15 \% \mathrm{AgO} / \mathrm{SiO}_{2}$ preparation, the same procedure was used. It was started with dissolving the desire amount of Tetraethylorthosilicate (TEOS) into ethanol. The solution was stirring for $30 \mathrm{~min}$. and then a stoichiometric amount of water was added into the solution to obtain hydrolysis reaction. The solution was continuing stirring. The known amount of nitric acid was added to peptize the solution. The known amount of cerium nitrate or silver nitrate was added into the solution. The obtained solution was stirring for $30 \mathrm{~min}$. and then the known amount of titanium isopropoxide was added and the solution was kept stirring for another $30 \mathrm{~min}$. to obtain the uniformity. The process of drying and calcining was followed the procedure of a $30 \mathrm{TiO}_{2} / \mathrm{SiO}_{2}$ preparation.

Sample characterization: Average crystalline sizes of each oxide were determined by Scherrer's equation using the X-ray line broadening from X-ray diffraction, Bruker AXS model D 8 Discover equipped with a $\mathrm{CuK} \alpha$ radiation with a nickel filter. Diffraction intensity was measured in the 2 theta ranges between 20 and $85^{\circ}$, with a step of $0.02^{\circ}$ for $8 \mathrm{sec}$ point ${ }^{-1}$.

\section{RESULTS AND DISCUSSION}

As been known, phase transformation of titanium dioxide depends on the calcination temperatures.

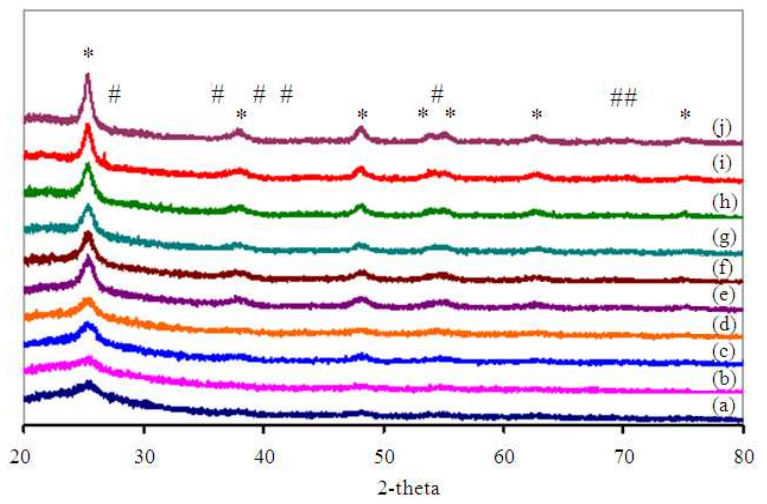

Fig. 1: XRD patterns of a $30 \% \mathrm{TiO}_{2} / \mathrm{SiO}_{2}$ calcined at different temperatures: (a) $350^{\circ} \mathrm{C}$; (b) $400^{\circ} \mathrm{C}$; (c) $450^{\circ} \mathrm{C}$; (d) $500^{\circ} \mathrm{C}$; (e) $600^{\circ} \mathrm{C}$; (f) $650^{\circ} \mathrm{C}$; (g) $700^{\circ} \mathrm{C}$; (h) $750^{\circ} \mathrm{C}$; (i) $800^{\circ} \mathrm{C}$; (j) $850^{\circ} \mathrm{C}$ and *: Represents standard peak position of $\mathrm{TiO}_{2}$ anatase phase, \#: Represents standard peak position of $\mathrm{TiO}_{2}$ rutile phase

For pure titanium dioxide, it was found that an increase in calcined temperatures led to changes of anatase to rutile. Qingju et al. (2002) observed the anatase occurred at the most when the sample was calcined at temperature of $450^{\circ} \mathrm{C}$ and further increasing in calcined temperature rutile phase appeared. At calcined temperature of $800^{\circ} \mathrm{C}$, titanium dioxide was completely in the form of rutile. In this research, the study of titanium dioxide phase transformation in the mixed oxide of titanium and other was investigated. The results were showed as following:

Phase and average crystallite size of a $30 \% \mathrm{TiO}_{2} / \mathrm{SiO}_{2}$ : Samples containing $30 \% \mathrm{TiO}_{2}$ and $70 \% \mathrm{SiO}_{2}$ were prepared by sol gel. The obtained solid powders were calcined at different temperatures from $350-850^{\circ} \mathrm{C}$ with increments of $50^{\circ} \mathrm{C}$. All samples were analyzed for their phase and average crystallite sizes by X-Ray Diffraction method (XRD). The results were shown in Fig. 1.

XRD measurements were performed in order to verify the occurrence of $\mathrm{TiO}_{2}$ phases at differences in calcined temperatures. Fig. 1 shows the XRD diffraction patterns obtained with $2 \theta=20-80^{\circ}$. * represents peak positions of $\mathrm{TiO}_{2}$ anatase phase at 25.4, 38.1, 48.1, 54.8, 62.5 and $75.1^{\circ}$. \# represents standard peak position of $\mathrm{TiO}_{2}$ rutile phase at 27.4, 36.1, 41.2, 56.6, 69.1 and $69.9^{\circ}$. These data were obtained from the references of spinel code 00-021-1272 and 01-076-0317, respectively, attached with the XRD instrument. Figure 1a is an XRD pattern of the sample calcined at $350^{\circ} \mathrm{C}$. As can be seen, the XRD pattern was quite smooth except at $25.4^{\circ}$ 
appearing as a small hill. An increasing of calcined temperatures increased intensity of peaks at this position and the peaks were getting sharp as been seen in Fig.1ac. Further increasing in calcined temperatures to $500^{\circ} \mathrm{C}$ increased a number of peak positions matching with peak positions of $\mathrm{TiO}_{2}$ anatase phase. The peak positions were found at 25.4, 38.1, 48.1, 54.862 .5 and 53.9 . These peak positions appeared in the samples calcined at 500$850^{\circ} \mathrm{C}$ and the intensities of each peaks increased with increasing of calcined temperatures. These results indicated that at low calcined temperatures, it was an amorphous structure appearing in the sample. An increase in calcined temperatures increased crystallinity of titanium dioxide and anatase phase was appeared in the samples calcined at temperature $450-850^{\circ} \mathrm{C}$. Interestingly, no rutile phase was observed in the all samples. Kumar et al. (1999) prepared a $90 \% \mathrm{TiO}_{2} / \mathrm{SiO}_{2}$ by cohydrolysis method and the samples were calcined at 800 and $1000^{\circ} \mathrm{C}$. They found that $\mathrm{TiO}_{2}$ was in only anatase phase for both calcined temperatures while a sample contained $95 \% \quad \mathrm{TiO}_{2}$ and $5 \% \mathrm{SiO}_{2}, \mathrm{TiO}_{2}$ was in anatase phase at calcined temperature of $800^{\circ} \mathrm{C}$ and $\mathrm{TiO}_{2}$ was found in rutile phase at calcined temperature of $1000^{\circ} \mathrm{C}$. The addition of silica in the samples resulted in an increase of anatase-rutile phase transformation temperature.

From XRD results, average crystallite sizes of $\mathrm{TiO}_{2}$ were calculated using Scherer equation. The results were showed in Table 1.

As in Table 1, average crystallite sizes of titanium dioxide increased with an increase of calcined temperatures. The XRD pattern of a sample calcined at $350^{\circ} \mathrm{C}$ was a bump and this could be described as

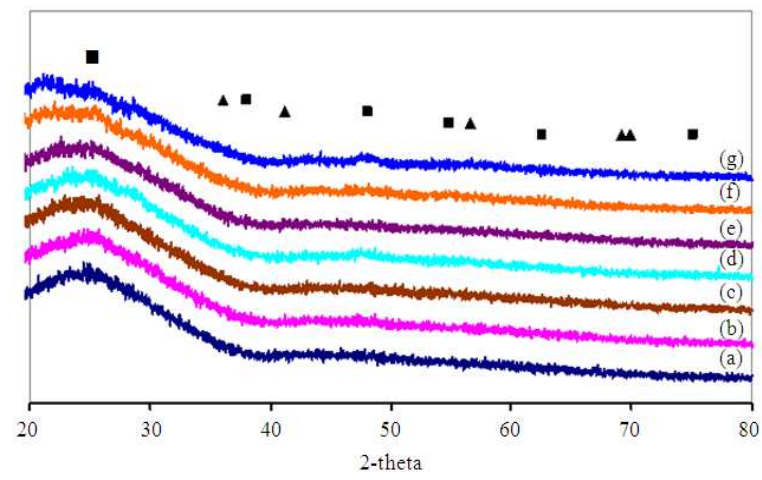

Fig. 2: XRD patterns of a $30 \% \mathrm{TiO}_{2} / 15 \% \mathrm{CeO}_{2} / \mathrm{SiO}_{2}$ calcined at different temperatures: (a) $350^{\circ} \mathrm{C}$; (b) $400^{\circ} \mathrm{C}$; (c) $450^{\circ} \mathrm{C}$; (d) $500^{\circ} \mathrm{C}$; (e) $550^{\circ} \mathrm{C}$; (f) $600^{\circ} \mathrm{C} ;(\mathrm{g}) 700^{\circ} \mathrm{C}$ and $\cdot$ : Represents standard peak position of $\mathrm{TiO}_{2}$ anatase phase, $\mathbf{\Delta}$ : Represents standard peak position of $\mathrm{TiO}_{2}$ rutile phase either an amorphous structure of the oxide or a crystallite structure and the particles were well dispersed in the samples. An increase of calcined temperatures from $350-850^{\circ} \mathrm{C}$ increased an average crystallite size of titanium dioxide from less than 3 $11.1 \mathrm{~nm}$. The sample calcined at $850^{\circ} \mathrm{C}$ has the largest crystallite size of $11.1 \mathrm{~nm}$. This was due to the agglomeration of $\mathrm{TiO}_{2}$ at high temperatures (Tian et al., 2009).

Phase and average crystallite size of a $30 \% \mathrm{TiO}_{2} / \mathbf{1 5} \% \mathrm{CeO}_{2} / \mathrm{SiO}_{2}$ : The samples contained $30 \% \mathrm{TiO}_{2}, 15 \% \mathrm{CeO}_{2}$ and $55 \% \mathrm{SiO}_{2}$ were calcined at different temperatures. The results from XRD showed in Fig. 2.

XRD measurements were performed in order to verify the occurrence of $\mathrm{TiO}_{2}$ phases at differences in calcite temperatures. Figure 2 shows the XRD diffraction patterns obtained with $2 \theta=20-80$. - represents peak positions of $\mathrm{TiO}_{2}$ anatase phase at 25.4, 38.1, 48.1, 54.8, 62.5 and $75.1^{\circ}$. $\Delta$ represents standard peak position of $\mathrm{TiO}_{2}$ rutile phase at 27.4, 36.1, 41.2, 56.6, 69.1 and $69.9^{\circ}$. These data were obtained from the references of

Table 1: Average crystallite sizes of the $30 \% \mathrm{TiO}_{2} / \mathrm{SiO}_{2}$ samples calcined at different temperatures

\begin{tabular}{lc} 
Calcined temperature $\left({ }^{\circ} \mathrm{C}\right)$ & Average size $(\mathrm{nm})$ \\
\hline 350 & $<3.0$ \\
400 & 4.9 \\
450 & 5.4 \\
500 & 5.8 \\
600 & 6.7 \\
650 & 8.2 \\
700 & 8.6 \\
750 & 8.8 \\
800 & 10.2 \\
850 & 11.1 \\
\hline
\end{tabular}

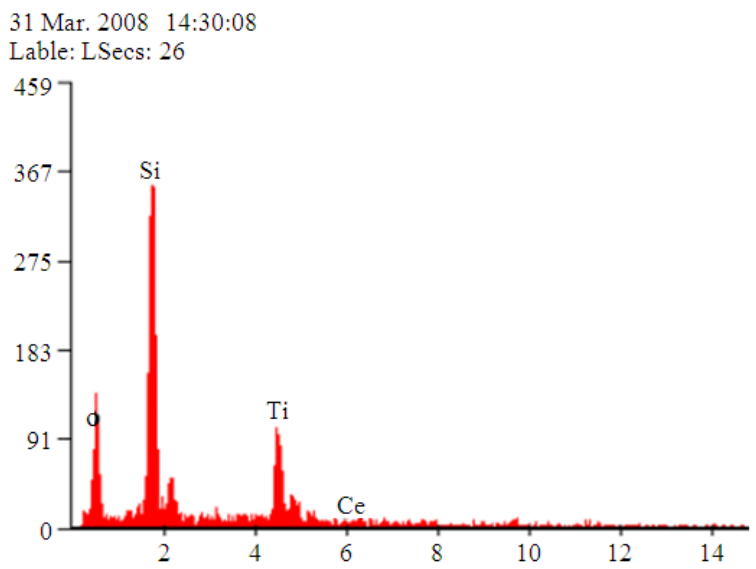

Fig. 3: EDX results for a $30 \% \mathrm{TiO}_{2} / 15 \% \mathrm{CeO}_{2} / \mathrm{SiO}_{2}$ sample calcined at $450^{\circ} \mathrm{C}$ 
Table 2: Chemical compositions obtained from EDX comparing with those of preparation

\begin{tabular}{llll}
\hline Element & Preparation (\%) & EDX (\%) & Error (\%) \\
\hline $\mathrm{Ti}$ & 17.9 & 19.6 & 8.9 \\
$\mathrm{Si}$ & 25.7 & 27.5 & 7.0 \\
$\mathrm{Ce}$ & 12.2 & 11.8 & 2.9 \\
$\mathrm{O}$ & 44.1 & 41.0 & 6.9 \\
\hline
\end{tabular}

Table 3: Average crystallite sizes of substances in samples contained $30 \% \quad \mathrm{TiO}_{2}, 15 \% \mathrm{Ag}$ and $55 \% \mathrm{SiO}_{2}$. Each sample was calcined at different temperatures

\begin{tabular}{lccc}
\hline & \multicolumn{3}{c}{ Crystallite size (nm) } \\
& \multicolumn{3}{c}{$\mathrm{TiO}_{2}$} \\
& --o-------- \\
Calcined temperature $\left({ }^{\circ} \mathrm{C}\right)$ & Anatase & Rutile & $\mathrm{Ag}$ \\
\hline 350 & 8.1 & - & - \\
400 & 6.2 & - & 16.8 \\
450 & 8.1 & - & 20.5 \\
500 & 8.9 & - & 21.7 \\
550 & 11.2 & - & 19.3 \\
600 & 10.6 & - & 24.6 \\
650 & 10.7 & - & 30.7 \\
700 & 24.1 & 32.6 & 32.0 \\
750 & 35.4 & 37.6 & 33.5 \\
800 & 36.4 & 48.9 & 36.9 \\
850 & 36.3 & 46.7 & 36.3 \\
\hline
\end{tabular}

spinel code 00-021-1272 and 01-076-0317, respectively, attached with the XRD instrument. As can be observed from the XRD patterns of all samples, there were no peak positions appeared except the bumps at $2 \theta=25^{\circ}$. It means that either all particles are well dispersed in the samples or there was an amorphous structure existing in the samples. However, an increase in calcined temperatures was not affected to the structure at all. Further investigation was conducted with EDX to determine the chemical composition in the sample. The results showed in Fig. 3.

As can be seen in Fig. 3, the results indicated the presence of titanium, cerium, silicon and oxygen in the sample. The composition of each atom was reported in Table 2.

From Table 2, the sample contained $30 \% \mathrm{TiO}_{2}$, $15 \% \mathrm{CeO}_{2}$ and $55 \% \mathrm{SiO}_{2}$ calcined at $450^{\circ}$ was analyzed for their chemical composition using EDX. The results indicated that there were $19.6 \% \mathrm{Ti}, 27.5 \% \mathrm{Si}, 11.8 \% \mathrm{Ce}$ and $41.0 \% \mathrm{O}$ in the sample. Comparing these data with those of calculating from the precursors during the preparation, it was found that there were $17.9 \% \mathrm{Ti}$, $25.7 \% \mathrm{Si}, 12.2 \% \mathrm{Ce}$ and $44.1 \% \mathrm{O}$ and these brought about to errors less than $10 \%$ for each element. The differences in results from preparation and those from EDX may cause from the loss of chemicals during preparation. Consequently, the results from EDX confirmed that all chemicals were present in the samples even though no peak positions of $\mathrm{TiO}_{2}$ and $\mathrm{CeO}_{2}$ were observed from XRD.

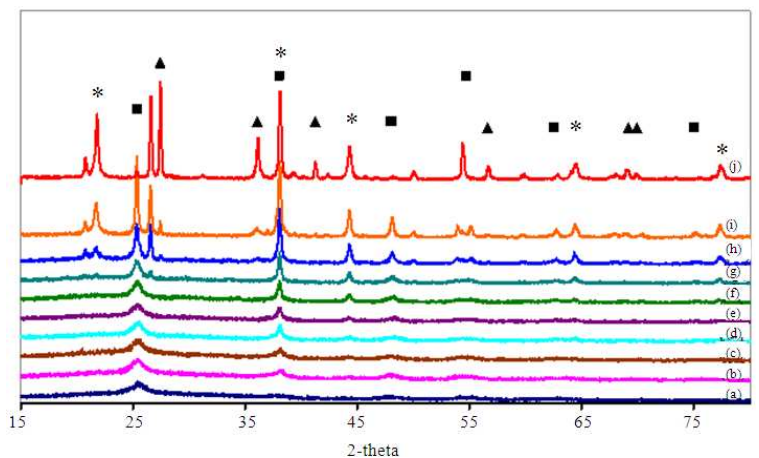

Fig. 4: XRD patterns of a $30 \% \mathrm{TiO}_{2} / 15 \% \mathrm{AgO} / \mathrm{SiO}_{2}$ calcined at different temperatures: (a) $350^{\circ} \mathrm{C}$; (b) $400^{\circ} \mathrm{C}$; (c) $450^{\circ} \mathrm{C}$; (d) $500^{\circ} \mathrm{C}$; (e) $600^{\circ} \mathrm{C}$; (f) $650^{\circ} \mathrm{C}$; (g) $700^{\circ} \mathrm{C}$; (h) $750^{\circ} \mathrm{C}$; (i) $800^{\circ} \mathrm{C}$; (j) $850^{\circ} \mathrm{C}$ and $*$ : Represents standard peak position of $\mathrm{Ag}, \cdot:$ Represents standard peak position of $\mathrm{TiO}_{2}$ anatase phase, $\mathbf{\Delta}$ : Represents standard peak position of $\mathrm{TiO}_{2}$ rutile phase

Phase and average crystallite size of a 30\% $\mathbf{T i O}_{2} / \mathbf{1 5} \% \mathbf{A g O} / \mathrm{SiO}_{2}$ : The samples contained $30 \%$ $\mathrm{TiO}_{2}, 15 \% \mathrm{AgO}$ and $55 \% \quad \mathrm{SiO}_{2}$ were calcined at different temperatures. The results from XRD showed in Fig. 4.

XRD measurements were performed in order to verify the occurrence of $\mathrm{TiO}_{2}$ phases at differences in calcined temperatures. Figure 4 shows the XRD diffraction patterns obtained with $2 \theta=15-80^{\circ}$. * represents peak positions of $\mathrm{Ag}$ at 21.8, 38.1, 44.3, 64.5 and $77.4^{\circ}$. - represents peak positions of $\mathrm{TiO}_{2}$ anatase phase at $25.4,38.1,48.1^{\circ}, 54.8^{\circ} 62.5^{\circ}$ and $75.1^{\circ}$. $\Delta$ represents standard peak position of $\mathrm{TiO}_{2}$ rutile phase at 27.4, 36.1, 41.2, 56.6, 69.1 and 69.9 . These data were obtained from the references of spinel code 01-089-3722, 00-021-1272 and 01-076-0317, respectively, attached with the $\mathrm{XRD}$ instrument. In Fig. 2a, XRD pattern of the sample calcined at $350^{\circ} \mathrm{C}$ indicated an amorphous structure of the oxide. An increase in calcined temperatures increased the peak intensity and appearing of peaks at different angles. Most likely, these peaks were peak positions of $\mathrm{TiO}_{2}$ anatase phase. Up until the calcined temperature of $500^{\circ} \mathrm{C}$, peak positions of $\mathrm{Ag}$ appeared in the XRD patterns. Each peak intensity increased with an increase of calcined temperatures until calcined temperatures of $700^{\circ} \mathrm{C}$, rutile phase appeared. Further increasing in calcined temperatures increased peak intensities of all compounds. These results indicated that the anataserutile phase transformation depended on calcined temperatures. Moreover, for a sample of titanium dioxide cooperated with other oxides, the phase 
transformation temperatures were higher that that of pure compound (Guan, 2005).

From XRD results, average crystallite sizes of $\mathrm{TiO}_{2}$ were calculated using Scherer equation. The results were showed in Table 2.

As can be seen from Table 2, average crystallite sizes increased with an increase of calcined temperatures for all compounds. The sample calcined at $800^{\circ} \mathrm{C}$ has the biggest crystallite sizes for anatase, rutile and silver. For the samples containing anatase and rutile phases, average crystallite size of anatase was smaller than that of rutile at any calcined temperatures. Ag appeared in the sample calcined at temperatures greater that $400^{\circ} \mathrm{C}$. Interestingly, the preparation method was sol gel. Theoretically, the final product from this method is oxide. This was due to the condensation reaction (Brinker et al., 1990). However, in this experiment, the amount of water added during the hydrolysis reaction was less that the stoichiometric amount. That could be the reason for obtaining $\mathrm{Ag}$ instead of $\mathrm{Ag}_{2} \mathrm{O}$.

\section{CONCLUSION}

- $\quad$ Phase transformation of titanium dioxide depends on calcined temperatures

- The addition of other oxides such as silica, cerium or silver can effectively suppress the anatase-rutile phase transformation and resulted in an increase of anatase-rutile phase transformation temperatures

- Anatase phase was only species found in $30 \% \mathrm{TiO}_{2} / \mathrm{SiO}_{2}$ samples calcined at temperatures up to $850^{\circ} \mathrm{C}$

- The addition of cerium oxide in mixed oxide of titanium and silica led to well dispersion of all oxides in the samples

- Average crystallite sizes increased with an increase in calcined temperatures

- The addition of silver in mixed oxide of titanium and silica lowered the anatase-rutile phase transformation temperatures to $700^{\circ} \mathrm{C}$

\section{ACKNOWLEDGEMENT}

This research has been granted by the Faculty of Engineering, Burapha University under the contract \# $35 / 2550$.

\section{REFERENCES}

Besor, A.S., A.V. Vorontsor and V.N. Parmon, 2009. Fast adsorptive and photocatalytic purification of air form acetone and dimethyl methyl phosphonate by $\mathrm{TiO}_{2}$ aerosol. Applied Catal. B: Environ., 89: 602-612. DOI: 10.1016/J.APCATB.2009.01.024
Brinker, J.C., W. George and S. Scherrer, 1990. Sol-gel science: The physics and chemistry of sol-gel processing. Boston, Acad, ISBN: 0-12-134970-5, 1990.

Guan, K., 2005. Relationship between photocatalytic activity, hydrophilicity and self-cleaning effect of $\mathrm{TiO}_{2} / \mathrm{SiO}_{2}$ composite film. Surface Coat. Technol., 191: 155-160. DOI: 10.1016/j.surfcoat.2004.02.022

Houmard, M., D. Riassetto, F. Roussel, A. Bourgeois and G. Berthome, 2007. Morphology and natural wettability properties of sol-gel derived $\mathrm{TiO}_{2}-\mathrm{SiO}_{2}$ composite thin films. Applied Surface Sci., 254: 1405-1414. DOI: 10.1016/j.apsusc.2007.06.072

Kontos, A.I., A.G. Kontos, D.S. Tsoukleris, G.D. Vlachos and P. Falaras, 2007. Superhydrophilicity and photocatalytic property of nanocrystalline Titania sol-gel films. Thin Solid Films, 515: 7370-7375. DOI: 10.1016/J.TSF.2007.02.082

Kumar, S.R., C.S. Asha, K. Vasudevan, R. Suja and P. Mukundan, 1999. Phase transformation in solgel titania containing silica. Mater. Lett., 38: 161-166. DOI: 10.1016/S0167-577X(98)00152-9

Liu, Z., X. Zhang, T. Murakami and A. Fujishima, 2008. Sol-gel $\mathrm{SiO}_{2} / \mathrm{TiO}_{2}$ bilayer films with selfcleaning and antireflection properties. Solar Energy Mater. Solar Cells, 92: 1434-1438. DOI: 10.1016/J.SOLMAT.2008.06.005

Meen, T.H., W. Water, W.R. Chen, S.M. Chao and L.W. Ji, 2009. Applications of $\mathrm{TiO}_{2}$ nano-particles on the electrode of dye-sensitized solar cells. J. Phys. Chem. Solids, 70: 472-476. DOI: 10.1016/J.JPCS.2008.12.002

Qingju, L., W. Xinghui, W. Baoling and L. Qiang, 2002. Preparation and super-hydrophilic properties of $\mathrm{TiO}_{2} / \mathrm{SnO}_{2}$ composite thin film. Mater. Res. Bull., 37: 2255-2262. DOI:10.1016/S00255408(02)00972-8

Tian, G., K. Pan, H. Fu, L. Jing and W. Zhou, 2009. Enhanced photocatalytic activity of S-doped $\mathrm{TiO}_{2}-$ $\mathrm{ZrO}_{2}$ nanoparticles under visible-light irradiation. J. Hazard. Mater., 166: 939-944. DOI:10.1016/j.jhazmat.2008.11.090 